\title{
Capacity of Erythromycin Phytoremediation by Differential Aquatic Macrophytes
}

\author{
Daiane Cristina Rocha 1, Camila da Silva Rocha 1, Leticia Yoshie Kochi 1, Gabriela Breternitz \\ Ribeiro ${ }^{1}$, Daniela Nogueira Moraes Carneiro ${ }^{2}$ and Marcelo Pedrosa Gomes ${ }^{1}$ \\ 1 Laboratório de Fisiologia de Plantas sob Estresse, Departamento de Botânica, Setor de Ciências Biológicas, \\ Universidade Federal do Paraná, Avenida Coronel Francisco H. dos Santos, 100, Centro Politécnico, Jardim \\ das Américas, C.P. 19031, Curitiba 81531-980, Paraná, Brazil \\ 2 Departamento de Fitotecnia e Fitossanidade, Setor de Ciências Agrárias, Universidade Federal do Paraná, \\ Rua dos Funcionários, 1540, Juvevê, Curitiba CEP 80035-050, Paraná, Brazil
}

\begin{abstract}
Despite technological advances, wastewater treatment systems are still inefficient in the complete removal of antibiotic residues, making the presence of these chemicals in the environment a problem for the aquatic community in addition to contributing to the selection and spread of microbial resistance. As a sustainable alternative, phytoremediation uses the ability of aquatic plants to purify water, which, among other factors, depends on the intrinsic characteristics of each species. Thus, we investigated the capacity for erythromycin removal between different free-floating (Salvinia molesta and Lemna minor) and submerged macrophyte species (Myriophyllum aquaticum and Rotala rotundufolia). Plants were submitted for 7 days to the antibiotic $\left(0\right.$ and $\left.1.7 \mu \mathrm{g} \cdot \mathrm{L}^{-1}\right)$ in growth media. Parallel experiments were conducted at the same conditions in flasks without plants to evaluate erythromycin degradation. The antibiotic concentrations in growth solution were evaluated at the beginning (T0) and final time of exposure (T7) while they were evaluated in whole plants at T7. Degradation of erythromycin occurred, however, its concentration in the growth media of flasks with plants were significantly lower. The antibiotic was also detected in plants, indicating their capacity for erythromycin removal. Removal capacity was greater in submerged ( $31 \%$ to $44 \%$ ) than in floating species (9\% to $12 \%$ ). Similarly, the concentration of erythromycin in the plants were greater in submerged plants. The antibiotic was not detected either in plants or growth solution of the control treatment. Thus, although the four species of macrophytes studied are capable of removing erythromycin from the solution, the submerged species have greater potential for remediation and should, when possible, be prioritized in phytoremediation projects.
\end{abstract}

Funding: This research was financed by the Brazilian National Council for Scientific and Technological Development (CNPq, Financial Code 406190/2018-6). M.P.G received a productivity fellowship from CNPq. 